\title{
Initial Experience and Outcomes with Cytoreductive Surgery and Hyperthermic Intraperitoneal Chemotherapy for the Management of Peritoneal Carcinomatosis in the Bahamas \\ T Humes $^{1}$, D Major $^{1}$, A Frankson ${ }^{2}, \mathrm{M} \mathrm{Weech}^{3}$, WP Francis ${ }^{1}$
}

\begin{abstract}
Background: Cytoreductive Surgery (CRS) with heated intraperitoneal chemotherapy (HIPEC) is a treatment option with curative intent for selected patients with peritoneal carcinomatosis (PC). The aim of our study was to report our initial experience with CRS and HIPEC performed by a specialized team in a low volume setting. We set out to determine the safety and efficacy of this treatment and also look at our outcomes with respect to perioperative complications and survival.
\end{abstract}

Methods: A prospective database of patients treated with CRS and HIPEC was maintained since 2010. Demographic, tumor and treatment factors as well as postoperative outcomes were prospectively recorded.

Results: Between 2010 and 2015 a total of seven patients underwent CRS and HIPEC. PC originated from colorectal carcinoma in five patients and appendix cancer in two patients. Mean age was 52 years, median peritoneal carcinoma index (PCI) was 13, mean operative time was 662 minutes and median blood loss was $1300 \mathrm{cc}$. Fourteen percent of patients developed a complication, there were no 30 day mortality. The median length of stay was 14 days. After an overall 19 month follow-up the overall mean survival was 48.83 months.

Conclusion: CRS and HIPEC seems a safe procedure for PC in the Bahamas. Favorable longterm survival was achieved in this population of highly selected patients with PC.

Keywords: Cytoreductive surgery, HIPEC, peritoneal carcinomatosis

From: ${ }^{1}$ Department of Surgery, Princess Margaret Hospital, Nassau, ${ }^{2}$ UWI School of Medicine and Research, and ${ }^{3}$ Department of Anesthesia Princess Margaret Hospital Nassau Bahamas

Correspondence: Dr WP Francis, 72 Collins Avenue, P O Box SS19633, Nassau, Bahamas. Fax: 1-242-356-0223, E-mail: csbresearchdocs@gmail.com 


\section{INTRODUCTION}

Peritoneal Carcinomatosis (PC) has generally been regarded to be the terminal stage of cancer progression and carries a very poor prognosis. Population base studies have reported the incidence of synchronous peritoneal metastases to be between 4.3 and $4.8 \%$ while metachronous metastases is reported at $4.2 \%(1,2)$. PC from colorectal origin has been reported to have a median overall survival of 5.2 months (3). Systemic chemotherapy has been shown to be ineffective because of relative chemoresistance due to lack of tissue penetration in PC (4). Patients with PC have a poorer prognosis than patients with metastasis to other sites, independent of the chemotherapy regime used for treatment (5).

The introduction of Cytoreductive Surgery (CRS) and Hyperthermic Intraperitonel Chemotherpay (HIPEC) to treat PC has provided survival benefits (6). CRS and HIPEC has become the preferred treatment option for many peritoneal surface malignancies such as peritoneal metastases from colorectal cancer, malignant peritoneal mesothelioma and psuedomyxoma peritonei [PMP] (7). The procedure consists of two phases; a cytoreductive phase with local disease control by macroscopic complete cytoreductive surgery followed by HIPEC to remove microscopic residual disease completely. Five-year survival rates of 19 to $51 \%$ have been reported for PC from colorectal origin and 73-86\% for PMP treated with CRS and HIPEC (8-10).

While this procedure has demonstrated survival benefit, there have been reports of high morbidity, which has prevented its wide acceptance. Two reports have demonstrated acceptable morbidity and mortality at high volume centers however $(11,12)$. In the Caribbean there are no high volume academic centers, however similar outcomes have been reported from specialized teams at community hospitals (13). 
The aim of our study was to report our initial experience with CRS and HIPEC performed by a specialized team in a low volume setting. We set out to determine the safety and efficacy of this treatment and also look at our outcomes with respect to perioperative complications and survival.

\section{SUBJECTS AND METHODS}

Between January 2010 and July 2015 we prospectively collected data on all consecutive patients with PC who were treated with CS and HIPEC. A total of seven patients were treated during the study period. The patients were diagnosed with PC from appendix (two) and colorectal (five) origin. PC of appendiceal origin were classified according to Ronnett's system as diffuse peritoneal adenomucinosis (DPAM) or peritoneal mucinous carcinomatosis [PMAC] (14). Informed consent was obtained from all patients and the ethics committee approved the study.

For all patients, the extent of PC was scored intraoperatively using the peritoneal cancer index (PCI), as described by sugarbaker (15). Cytoreductive surgery was performed by a single surgeon (WF), with resection of all visible peritoneal deposits and in two cases, simultaneous liver resection was required. The completeness of cytoreduction (CCR) was scored as described by Sugarbaker (15): CCR-0 (no residual macroscopic deposits), CCR-1 (residual nodules $<2.5 \mathrm{~mm}$ in diameter), and CCR-2 (residual nodules $>2.5 \mathrm{~mm}$ ). All patients were then treated with a standardized protocol consisting of HIPEC with Oxaliplatin (400mg in $3 \mathrm{~L}$ of Dianeal, circulated for $60 \mathrm{~min}$ at $40-42^{\circ} \mathrm{C}$ ) with an intravenous dose of 5-FU (800mg) given one hour prior to the HIPEC. The open coliseum technique was used to circulate in all cases. All patients were admitted to the ICU post operatively. 
Demographic, tumor and treatment factors as well as postoperative outcomes were prospectively recorded. Intraoperative parameters such as blood loss, transfusion requirements, length of procedure, number of anastomosis and CCO score were measured. All complications were recorded prospectively and classified by Dindo-Clavien grade(16). Only major complications (grade III, IV or V) were included in the analysis. ICU and overall length of stay were also recorded. Overall survival was calculated from date of surgery to date of death or last follow-up. Progression free survival was recorded from date of surgery to first recurrence. Each recurrence was classified as local, regional or distant.

\section{Statistical analysis}

Categorical variables were described in absolute numbers and percentages. The measures of central tendency is reported as the median, mean and ranges as well as standard deviations accompanying the means. Survival analysis was done using the Kaplan-Meier survival method. All analyses were performed using SPSS 21(IBM SPSS Inc, Chicago IL 2013).

\section{RESULTS}

Seven patients underwent CRS and HIPEC during the study period. There were 4 males and 3 females; the mean age was 52 years (range 31-71, SD 11.98). There were 5 patients with PC from colorectal origin and 2 from appendix origin but with high grade histology. Median total operating time was 662 minutes (range 360-798, mean: 655.6, SD146). Median estimated blood loss was 1300 (range 100-2000, mean: 1142.9, SD 828) mls. (Table 1). Four patients required blood transfusions each requiring only 2 units of PRBC.

The median PCI was 13 (range 3-29, mean: 13.1, SD 9.2) and all patients had complete cytoreduction (CCO-0). One (14\%) patient had a major complication (grade III). This patient developed postoperative liver failure, after having a simultaneous right 
hepatectomy. She had synchronous peritoneal and liver metastasis and had received 12 cycles of Irinotecan base chemotherapy preoperatively. She had a prolonged length of stay but was eventually discharged once her liver function recovered (Table 2). The median length of stay was 14 days (range 10-68, mean: 20.6 SD 21.1) and there were no 30 or 90 day mortality during the study period.

Median follow-up for the group was 19 (range 19-65, mean: 29.7, SD 23.6) months. Overall mean survival for the group was 43.83 (range 13- 65, SD 11.6) months. In the group of patients with PC from colorectal origin, the mean survival was 52 (range 13-65, SD 11.2) months (Figure). One patient died in the colorectal group after 13 months because of complications of surgery for a high grade small bowel obstruction, at the time of her death she was disease free.

Mean survival for PC from appendix origin was 20 months. Both patients in the appendix group had high grade histology or PMCA as described by Ronnett(14). The first patient had a PCI of 29 and subsequently developed a recurrence in the porta hepatis and died after 19 months with widespread disease progression on chemotherapy. The second patient developed a local recurrence in the incision noticed at 6 months follow-up, his CT Pet scan did not show any other evidence of disease, he underwent resection and abdominal wall reconstruction and is now disease free at 16 months follow-up.

\section{DISCUSSION}

The combination of CRS and HIPEC is advocated for the management of PC and was first introduced in 1980 by Spratt and colleuages (17). The procedure has been modified over the years and the technique refined by Dr. Sugarbaker at the Washington Cancer Center and the procedure carries his name(6). The procedure involves complete tumor removal by means of 
stripping the peritoneum combined with often complex visceral resections. Heated intraperitoneal chemotherapy is then circulated within the abdomen to sterilize residual mucinous tumor nodules and to avoid entrapment of tumor cells in the early post operative scars.

The obvious benefits of HIPEC are the higher intraabdominal concentration which overcomes the chemoresistance of PC coupled with the decreased systemic levels which reduces the side effects (18). The penetration of hyperthermic chemotherapeutic agents have been limitied to a few millimeters and therefore the completeness of cytoreduction has prognostic significance and has been shown to be an independent predictor of survival(19). CRS and HIPEC morbidity has been reported to be in the range of $12-56 \%$ and mortality from $0-12 \%$ (11). High morbidity has been correlated with the extent of carcinomatosis, blood loss, transfusion requirement and number of organs resected $(20,21)$.

We present our initial experience with CRS and HIPEC at our center. To the best of our knowledge there are no reports of CRS and HIPEC performed in the Caribbean. The morbidity reported in this series was $14 \%$ and there were no 30 day procedure related mortality. This series does represent a highly selected group of patients managed by the same surgeon and anesthetic team in a considerable low resource environment. All patients were seen and managed by a multidisciplinary team before selected to undergo the procedure.

The overall survival of PC from colorectal origin was 52 months at 5 years which compares favorably to that reported in the literature. PC survival from high grade appendix lesions was 20 months and these patients demonstrated early recurrence of disease. Tabrizian et al reported a recurrence rate of $46 \%$ and $73.9 \%$ at 1 and 3 years for a cohort of PC from colorectal and appendiceal origin. Indicators for poor survival in this group were high PCI $(>16)$ and requirements for blood transfusion, the median time to recurrence was 12.4 months 
(22). Therefore despite a high rate of complete cytoreduction tumor burden and careful patients' selection remained the most important predictors for prolonged survival.

The limitation of this study is that it is retrospective and a very small population of highly selected patients. The number of patients does reflect the amount of treatable PC in the Bahamas. The incidence of colorectal cancer in the Bahamas is reported as 9.7 per 100,000 and population studies suggest that the burden of PC from colorectal cancer is reported as 4.8 $\%(1)$. Therefore we would expect to see approximately 1-2 cases of treatable PC per year in our population of 370,000 . One way to increase the experience would be to expand the service to include PC from ovarian origin and to offer the service to the entire Caribbean region.

Careful selection is extremely important in our setting because of the lack of resources and therefore only patients with low volume of disease and good performance status are selected as candidates for the procedure. Careful preoperative evaluation is necessary to determine the extent of PC. This presents a challenge as cross sectional imaging (CT scan) underestimates the extent of disease(23). The use of laparoscopy prior to laparotomy is a useful tool to better select those patients who may benefit from the procedure, this would warrant further investigation in our setting as it may allow us to better apply limited resources(22).

\section{CONCLUSION}

In summary this review represents our initial experience of CRS and HIPEC in the Bahamas. We have demonstrated that such complex procedures can be performed safely in a low resource environment by carefully selecting patients and utilizing a specialized team. 


\section{REFERENCES}

1. Segelman J, Granath F, Holm T, Machado M, Mahteme H, Martling A. Incidence, prevalence and risk factors for peritoneal carcinomatosis from colorectal cancer. Bri J Sur 2012; 99: 699-705. PubMed PMID: 22287157.

2. Lemmens VE, Klaver YL, Verwaal VJ, Rutten HJ, Coebergh JW, de Hingh IH. Predictors and survival of synchronous peritoneal carcinomatosis of colorectal origin: a population-based study. Int J Cancer 2011; 128: 2717-25. PubMed PMID: 20715167.

3. Sadeghi B, Arvieux C, Glehen O, Beaujard AC, Rivoire M, Baulieux J et al. Peritoneal carcinomatosis from non-gynecologic malignancies: results of the EVOCAPE 1 multicentric prospective study. Cancer 2000; 88: 358-63. PubMed PMID: 10640968.

4. Franko J, Shi Q, Goldman CD, Pockaj BA, Nelson GD, Goldberg RM, et al. Treatment of colorectal peritoneal carcinomatosis with systemic chemotherapy: a pooled analysis of north central cancer treatment group phase III trials N9741 and N9841. Journal of clinical oncology : official journal of the American Society of Clinical Oncology. 2012 Jan 20;30(3):263-7. PubMed PMID: 22162570. Pubmed Central PMCID: 3269953.

5. Klaver YL, Simkens LH, Lemmens VE, Koopman M, Teerenstra S, Bleichrodt RP, et al. Outcomes of colorectal cancer patients with peritoneal carcinomatosis treated with chemotherapy with and without targeted therapy. European journal of surgical oncology : the journal of the European Society of Surgical Oncology and the British Association of Surgical Oncology. 2012 Jul;38(7):617-23. PubMed PMID: 22572106.

6. Sugarbaker PH. Peritonectomy procedures. Annals of surgery. 1995 Jan;221(1):2942. PubMed PMID: 7826158. Pubmed Central PMCID: 1234492. 
7. Esquivel J, Sticca R, Sugarbaker P, Levine E, Yan TD, Alexander R, et al. Cytoreductive surgery and hyperthermic intraperitoneal chemotherapy in the management of peritoneal surface malignancies of colonic origin: a consensus statement. Society of Surgical Oncology. Annals of surgical oncology. 2007 Jan;14(1):128-33. PubMed PMID: 17072675.

8. Elias D, Lefevre JH, Chevalier J, Brouquet A, Marchal F, Classe JM, et al. Complete cytoreductive surgery plus intraperitoneal chemohyperthermia with oxaliplatin for peritoneal carcinomatosis of colorectal origin. Journal of clinical oncology : official journal of the American Society of Clinical Oncology. 2009 Feb 10;27(5):681-5. PubMed PMID: 19103728.

9. Glehen O, Gilly FN, Boutitie F, Bereder JM, Quenet F, Sideris L, et al. Toward curative treatment of peritoneal carcinomatosis from nonovarian origin by cytoreductive surgery combined with perioperative intraperitoneal chemotherapy: a multi-institutional study of 1,290 patients. Cancer. 2010 Dec 15;116(24):5608-18. PubMed PMID: 20737573.

10. Chua TC, Liauw W, Zhao J, Morris DL. Comparative analysis of perioperative intraperitoneal chemotherapy regimen in appendiceal and colorectal peritoneal carcinomatosis. International journal of clinical oncology. 2013 Jun;18(3):439-46. PubMed PMID: 22415741.

11. Sugarbaker PH, Alderman R, Edwards G, Marquardt CE, Gushchin V, Esquivel J, et al. Prospective morbidity and mortality assessment of cytoreductive surgery plus perioperative intraperitoneal chemotherapy to treat peritoneal dissemination of appendiceal mucinous malignancy. Annals of surgical oncology. 2006 May;13(5):635-44. PubMed PMID: 16523363. 
12. Kuijpers AM, Mirck B, Aalbers AG, Nienhuijs SW, de Hingh IH, Wiezer MJ, et al. Cytoreduction and HIPEC in the Netherlands: nationwide long-term outcome following the Dutch protocol. Annals of surgical oncology. 2013 Dec;20(13):422430. PubMed PMID: 23897008. Pubmed Central PMCID: 3827901.

13. Kerscher AG, Mallalieu J, Pitroff A, Kerscher F, Esquivel J. Morbidity and mortality of 109 consecutive cytoreductive procedures with hyperthermic intraperitoneal chemotherapy (HIPEC) performed at a community hospital. World journal of surgery. 2010 Jan;34(1):62-9. PubMed PMID: 20020294.

14. Ronnett BM, Zahn CM, Kurman RJ, Kass ME, Sugarbaker PH, Shmookler BM. Disseminated peritoneal adenomucinosis and peritoneal mucinous carcinomatosis. A clinicopathologic analysis of 109 cases with emphasis on distinguishing pathologic features, site of origin, prognosis, and relationship to "pseudomyxoma peritonei". The American journal of surgical pathology. 1995 Dec;19(12):1390-408. PubMed PMID: 7503361.

15. Harmon RL, Sugarbaker PH. Prognostic indicators in peritoneal carcinomatosis from gastrointestinal cancer. International seminars in surgical oncology : ISSO. 2005 Feb 8;2(1):3. PubMed PMID: 15701175. Pubmed Central PMCID: 549516.

16. Dindo D, Demartines N, Clavien PA. Classification of surgical complications: a new proposal with evaluation in a cohort of 6336 patients and results of a survey. Annals of surgery. 2004 Aug;240(2):205-13. PubMed PMID: 15273542. Pubmed Central PMCID: 1360123.

17. Spratt JS, Adcock RA, Muskovin M, Sherrill W, McKeown J. Clinical delivery system for intraperitoneal hyperthermic chemotherapy. Cancer research. 1980 Feb;40(2):256-60. PubMed PMID: 6766084. 
18. Sugarbaker PH, Landy D, Jaffe G, Pascal R. Histologic changes induced by intraperitoneal chemotherapy with 5-fluorouracil and mitomycin $\mathrm{C}$ in patients with peritoneal carcinomatosis from cystadenocarcinoma of the colon or appendix. Cancer. 1990 Apr 1;65(7):1495-501. PubMed PMID: 2107021.

19. Sugarbaker PH, Chang D. Results of treatment of 385 patients with peritoneal surface spread of appendiceal malignancy. Annals of surgical oncology. 1999 Dec;6(8):72731. PubMed PMID: 10622499.

20. Glehen O, Osinsky D, Cotte E, Kwiatkowski F, Freyer G, Isaac S, et al. Intraperitoneal chemohyperthermia using a closed abdominal procedure and cytoreductive surgery for the treatment of peritoneal carcinomatosis: morbidity and mortality analysis of 216 consecutive procedures. Annals of surgical oncology. 2003 Oct;10(8):863-9. PubMed PMID: 14527903.

21. Schmidt U, Dahlke MH, Klempnauer J, Schlitt HJ, Piso P. Perioperative morbidity and quality of life in long-term survivors following cytoreductive surgery and hyperthermic intraperitoneal chemotherapy. European journal of surgical oncology : the journal of the European Society of Surgical Oncology and the British Association of Surgical Oncology. 2005 Feb;31(1):53-8. PubMed PMID: 15642426.

22. Tabrizian P, Shrager B, Jibara G, Yang MJ, Romanoff A, Hiotis S, et al. Cytoreductive surgery and hyperthermic intraperitoneal chemotherapy for peritoneal carcinomatosis: outcomes from a single tertiary institution. Journal of gastrointestinal surgery : official journal of the Society for Surgery of the Alimentary Tract. 2014 May;18(5):1024-31. PubMed PMID: 24577736.

23. Chua TC, Al-Zahrani A, Saxena A, Glenn D, Liauw W, Zhao J, et al. Determining the association between preoperative computed tomography findings and postoperative outcomes after cytoreductive surgery and perioperative intraperitoneal chemotherapy 
for pseudomyxoma peritonei. Annals of surgical oncology. 2011 Jun;18(6):1582-9. PubMed PMID: 21207170. 
Table 1: Perioperative data

\begin{tabular}{llllll}
\hline Patient & $\begin{array}{l}\text { Length of } \\
\text { stay }\end{array}$ & $\begin{array}{l}\text { Length of } \\
\text { procedure }\end{array}$ & $\begin{array}{l}\text { Blood } \\
\text { loss }\end{array}$ & $\begin{array}{l}\text { ICU } \\
\text { stay }\end{array}$ & Morbidity \\
\hline PT 1 & 16 & 623 & 400 & 5 & II (NEUTROPENIA) \\
PT 2 & 11 & 360 & 100 & 2 & - \\
PT 3 & 68 & 798 & 2000 & 4 & III (LIVER FAILURE) \\
PT 4 & 14 & 793 & 2000 & 5 & - \\
PT 5 & 10 & 662 & 1300 & 2 & - \\
PT 6 & 15 & 698 & 400 & 2 & II (PNEUMONIA) \\
PT 7 & 10 & 655 & 1800 & 2 & II (ATRIAL \\
& & & & & FIBRILLATION) \\
MEDIAN & 14 & 662 & 1300 & 2 & \\
\hline
\end{tabular}

Table 2: Surgical treatment and survival

\begin{tabular}{|c|c|c|c|c|c|}
\hline Patient & Pathology & Surgery & PCI & $\mathrm{CC}$ & Survival \\
\hline PT 1 & COLORECTAL & $\begin{array}{l}\text { Abdominal wall, } \\
\text { omentectomy }\end{array}$ & 3 & 0 & Alive DF, 65 \\
\hline PT 2 & COLORECTAL & $\begin{array}{l}\text { Rt Colectomy, } \\
\text { omentectomy }\end{array}$ & 4 & 0 & Alive DF, 63 \\
\hline PT 3 & COLORECTAL & $\begin{array}{l}\text { PP, Left colectomy, } \\
\text { omentectomy, Rt } \\
\text { hepatectomy, }\end{array}$ & 13 & 0 & Dead, 13, DF \\
\hline PT 4 & APPENDIX HG & $\begin{array}{l}\text { PP, gastrectomy, } \\
\text { omentectomy, } \\
\text { colectomy, small } \\
\text { bowel resection, Rt \& } \\
\text { LT hemidiaphragm, }\end{array}$ & 29 & 0 & $\begin{array}{l}\text { Dead, } 20 \text { with } \\
\text { disease } \\
\text { progression }\end{array}$ \\
\hline PT 5 & COLORECTAL & $\begin{array}{l}\text { PP, omentectomy, } \\
\text { small bowel resection, }\end{array}$ & 17 & 0 & Alive DF, 19 \\
\hline PT 6 & APPENDIX HG & $\begin{array}{l}\text { Rt colectomy, } \\
\text { omentectomy, partial } \\
\text { hepatectomy, Rt } \\
\text { hemidiaphragm }\end{array}$ & 18 & 0 & $\begin{array}{l}\text { Alive DF , } 16 \\
\text { (Wound } \\
\text { recurrence } \\
\text { repeat surgery) }\end{array}$ \\
\hline PT 7 & COLORECTAL & $\begin{array}{l}\text { Omentectomy, Pelvic } \\
\text { peritonectomy }\end{array}$ & 8 & 0 & Alive DF, 12 \\
\hline
\end{tabular}

PCI Peritoneal cancer index

$\mathrm{CC}$ : Completeness of cytoreduction

PP: Pelvic peritonectomy (en-bloc removal of uterus, ovaries, rectosigmoidectomy, parietal peritonectomy to transverse umbilical line).

DF: Disease free 
CRS and HIPEC

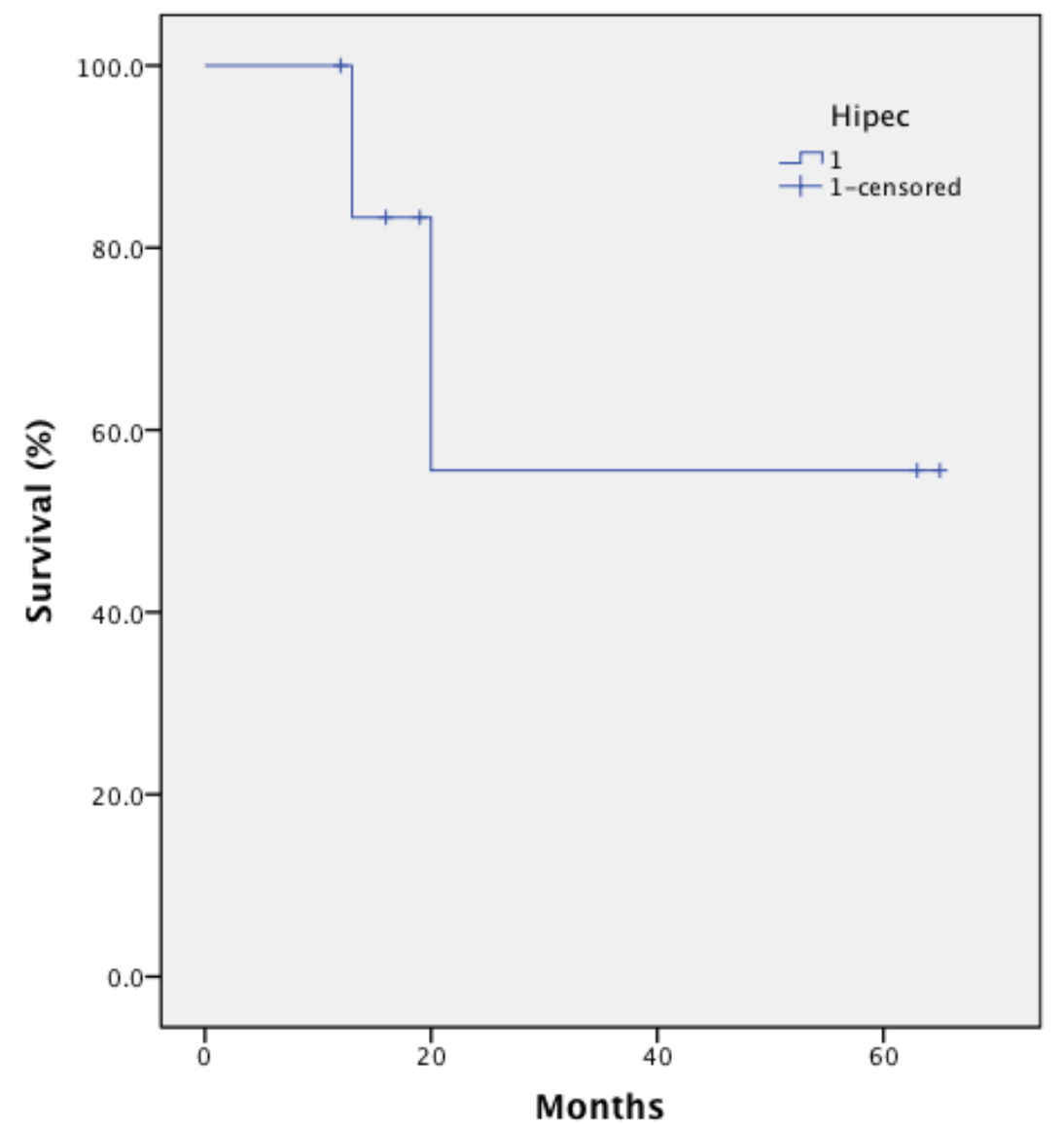

Figure: Survival curve for PC treated with CRS and HIPEC. 